\title{
The effectiveness of strategies to change organisational culture to improve healthcare performance: a systematic review
}

\author{
Elena Parmelli ${ }^{1} 2^{*}$, Gerd Flodgren ${ }^{1}$, Fiona Beyer ${ }^{1}$, Nick Baillie ${ }^{3}$, Mary Ellen Schaafsma ${ }^{4}$ and Martin P Eccles ${ }^{1}$
}

\begin{abstract}
Background: Organisational culture is an anthropological metaphor used to inform research and consultancy and to explain organisational environments. In recent years, increasing emphasis has been placed on the need to change organisational culture in order to improve healthcare performance. However, the precise function of organisational culture in healthcare policy often remains underspecified and the desirability and feasibility of strategies to be adopted have been called into question. The objective of this review was to determine the effectiveness of strategies to change organisational culture in order to improve healthcare performance.

Methods: We searched the following electronic databases: The Cochrane Central Register of Controlled Trials, MEDLINE, EMBASE, CINAHL, Sociological Abstracts, Web of Knowledge, PsycINFO, Business and Management, EThOS, Index to Theses, Intute, HMIC, SIGLE, and Scopus until October 2009. The Database of Abstracts of Reviews of Effectiveness (DARE) was searched for related reviews. We also searched the reference lists of all papers and relevant reviews identified, and we contacted experts in the field for advice on further potential studies. We considered randomised controlled trials (RCTs) or well designed quasi-experimental studies (controlled clinical trials (CCTs), controlled before and after studies (CBAs), and interrupted time series (ITS) analyses). Studies could be set in any type of healthcare organisation in which strategies to change organisational culture in order to improve healthcare performance were applied. Our main outcomes were objective measures of professional performance and patient outcome.

Results: The search strategy yielded 4,239 records. After the full text assessment, two CBA studies were included in the review. They both assessed the impact of interventions aimed at changing organisational culture, but one evaluated the impact on work-related and personal outcomes while the other measured clinical outcomes. Both were at high risk of bias. Both reported positive results.

Conclusions: Current available evidence does not identify any effective, generalisable strategies to change organisational culture. Healthcare organisations considering implementing interventions aimed at changing culture should seriously consider conducting an evaluation (using a robust design, e.g., ITS) to strengthen the evidence about this topic.
\end{abstract}

\section{Background}

Organisational culture is an anthropological metaphor used to inform research and consultancy and to explain organisational environments [1]. Several definitions of organisational culture can be found in literature [2]. They range from the extremely simple - 'the way we do

\footnotetext{
* Correspondence: elena.parmelli@unimore.it

'Institute of Health and Society, Newcastle University, Baddiley-Clark Building, Richardson Road, Newcastle upon Tyne, NE2 4AX, UK

Full list of author information is available at the end of the article
}

things around here' [3] - to the more complex such as that proposed by Schien: 'the pattern of shared basic assumption - invented, discovered or developed by a given group as it learns to cope with its problems of external adaptation and internal integration - that has worked well enough to be considered valid and therefore to be taught to new members as the correct way to perceive, think and feel in relationship to those problems' [4]. What appears to be consistent through all these definitions is that the term organisational culture

\section{Biomed Central}


pertains to the multiple aspects of what is shared among people within the same organisation: for example beliefs, values, norms of behaviour, routines, traditions, sensemaking, et al. Culture is therefore a lens through which an organisation can be understood and interpreted [5]. Scott et al. in 2003 [6] highlighted that culture is not merely the observable in social life, but also the shared cognitive and symbolic context within which a society can be understood. For this reason, they decided to adopt Schien's definition that seemed to better include all the different aspects of organisational culture. For this review we have chosen to do the same.

Increasing emphasis has been placed during recent years on the need to change organisational culture alongside structural reforms in order to pursue effective improvement of healthcare performance [7-9]. However, the management of culture change is a complicated task; its precise function in healthcare policy often remains underspecified and the desirability and feasibility of strategies to be adopted have been called into question [10].

A survey conducted in 275 English National Health Service (NHS) organisations in 2008 [1] highlighted that one-third of them currently used a culture assessment instrument to support their clinical governance activity, although most of this use related to one instrument (Manchester Patient Safety Framework [11]). Within this survey [1], Mannion et al. reviewed the literature about instruments available to health services researchers wishing to measure culture and culture change. They identified two-dozen tools used for culture assessment and having potential relevance to healthcare organisations; relatively few of these had been used to any extent in the NHS. Extant tools covered many of the most important organisational culture attributes, but their focus in use was on safety rather than on the assessment of dimensions of healthcare quality and performance. Moreover, little evaluation of the use and the practical application of these tools or how well they connect with ongoing policy, managerial, or service preoccupations is available. A similar message came from a more recent review in which Jung et al. [12] identified 70 qualitative or quantitative instruments for exploring organisational culture for formative, summative, or diagnostic reasons. They described the majority as 'at a preliminary stage of development' and concluded that there was 'no ideal instrument for cultural exploration.'

The idea that organisational culture can affect performance is based in particular on the assumption that they are related, but evidence from the research literature for this link is weak [13]. A review conducted by Scott et al. focused on this relationship. They qualitatively summarised ten empirical studies investigating the relationship between culture and performance and concluded that 'there is some evidence to suggest that organisational culture may be a relevant factor in healthcare performance, yet articulating the nature of that relationship proves difficult' [6]. More recently, Mannion et al. compared, in a multiple case study design, the cultural characteristics of 'high' and 'low' performing hospitals in the UK NHS [14]. They found that different cultural patterns could be identified within cases grouped by performance, and concluded that organisational culture is associated with performance, but they highlighted that the interpretation of their results should be tempered with a degree of caution because of some methodological issues.

Nonetheless, the management of organisational culture is increasingly viewed as a necessary part of health system reform [15-17]. In 2008, a survey conducted across a total of 325 English NHS primary and acute trusts reported that $98 \%$ of responding clinical governance managers saw the need to measure local culture in order to foster change for improved performance; nearly all of them (99\%) acknowledged the importance of understanding and shaping local cultures, but the majority $(88 \%)$ were also conscious that there are many challenges to overcome to implement and sustain beneficial culture change [5]. It is therefore timely and important to review the literature on the effectiveness of strategies to change organisational culture in order to improve healthcare performance.

The objectives of this review were: to determine the effectiveness of strategies to change organisational culture in improving healthcare performance and to examine the effectiveness of these strategies according to different patterns of organisational culture.

\section{Methods}

We considered randomised controlled trials (RCTs) or well designed quasi-experimental studies, controlled clinical trials (CCTs), controlled before and after studies (CBAs), and interrupted time series (ITS) analyses set in any type of healthcare organisation and investigating strategies to change organisational culture in order to improve healthcare performance. ITS analyses were eligible if they had a clearly defined point in time when the intervention occurred and three data collection points before and after the intervention to take into account secular trends and auto-correlation among measurements over time [18].

The two main outcomes of the review were: objective measures of professional performance such as prescription rates, the extent to which care is evidence based, quality of care; and objective measures of patient outcome such as mortality (standardised mortality ratio), condition-specific measures of outcome, quality of life, functional health status, and patients' satisfaction. 
We also report other included outcomes such as: objective measures of organisational performance (such as wait times, inpatient hospital stay times, and staff turnover rates); measures of organisational culture; economic outcomes (such as efficiencies and changes in costs); and measures of health practitioners' knowledge, attitudes, satisfaction.

To identify studies eligible for this review we searched the following electronic databases for primary studies: The Cochrane Central Register of Controlled Trials (The Cochrane Library 2009, Issue 4), MEDLINE - Ovid (1950 to October Week 3 2009), EMBASE - Ovid (1980 to 2009 Week 41), CINAHL - EBSCO (1980 to October 2009), Sociological Abstracts - CSA (1952 to October 2009), Social Science Citation Index - Web of Knowledge (1970 to October 2009), Science Citation Index Web of Knowledge (1970 to October 2009), Conference Proceedings - Web of Knowledge (1970 to October 2009), PsycINFO - Ovid (1806 to October Week 3 2009), Business and Management - OCLC FirstSearch (1995 to October 2009), EThOS (British Library), Index to Theses (1716 to October 2009), Intute, HMIC - Ovid (1979 to October 2009), SIGLE, Scopus (1823 to October 2009). Search strategies for primary studies incorporated the methodological component of the Cochrane Collaboration Effective Practice and Organisation of Care Review Group search strategy combined with selected index terms and free text terms. We translated the MEDLINE search strategy into the other databases using the appropriate controlled vocabulary as applicable. The full search strategies are presented in Additional File 1. We also searched the reference lists of all papers and relevant reviews identified, and we contacted experts in the field for advice on further potential studies. Finally, we searched the Database of Abstracts of Reviews of Effectiveness (DARE) for related reviews.

We downloaded all titles and abstracts retrieved by electronic searching to the reference management database EndNote, and removed duplicates. At least two review authors (from EP, GF, MPE) independently examined the remaining references. We excluded those studies that clearly do not meet the inclusion criteria and obtained copies of the full text of potentially relevant references. At least two review authors (from EP, GF, MES, MPE, NB) independently assessed the eligibility of retrieved papers and extracted the data using a specifically developed checklist. We used the same criteria as those outlined in the Cochrane Handbook for Systematic Reviews of Interventions to evaluate data [19] and we resolved any disagreement by discussion and the involvement of an arbitrator (MPE) as necessary.

The risk of bias of the eligible studies was evaluated independently by at least two reviewers using the following criteria: RCTs, CCTs, and CBAs were assessed for generation of allocation sequence, concealment of allocation, baseline outcome measurements, baseline characteristics, incomplete outcome data, blinding of outcome assessor, protection against contamination, selective outcome reporting, and other risks of bias. ITS designs were also assessed for the independence of the intervention from other changes, the pre-specified shape of the intervention, and whether the intervention was likely or unlikely to affect data collection. Data were reported in natural units. Where baseline results were available from RCTs, CCTs, and CBAs, we reported pre-intervention and post-intervention means or proportions for both study and control groups. We calculated the adjusted (for any baseline imbalance) absolute change from baseline reported as the adjusted risk difference (ARD) calculated as: (Intervention Follow-up Intervention Baseline) - (Control Follow-up - Control Baseline).

\section{Results}

The search strategy identified 4,239 records. After the independent examination by the reviewers, we retrieved 13 articles potentially eligible for the review. Three more articles were identified from the reference lists of those retrieved. After full text assessment, two studies $[20,21]$ met the inclusion criteria (Figure 1). For a description of excluded studies and reasons for their exclusion see Additional File 2; of 14 studies, six were not aiming to change organisational culture, two

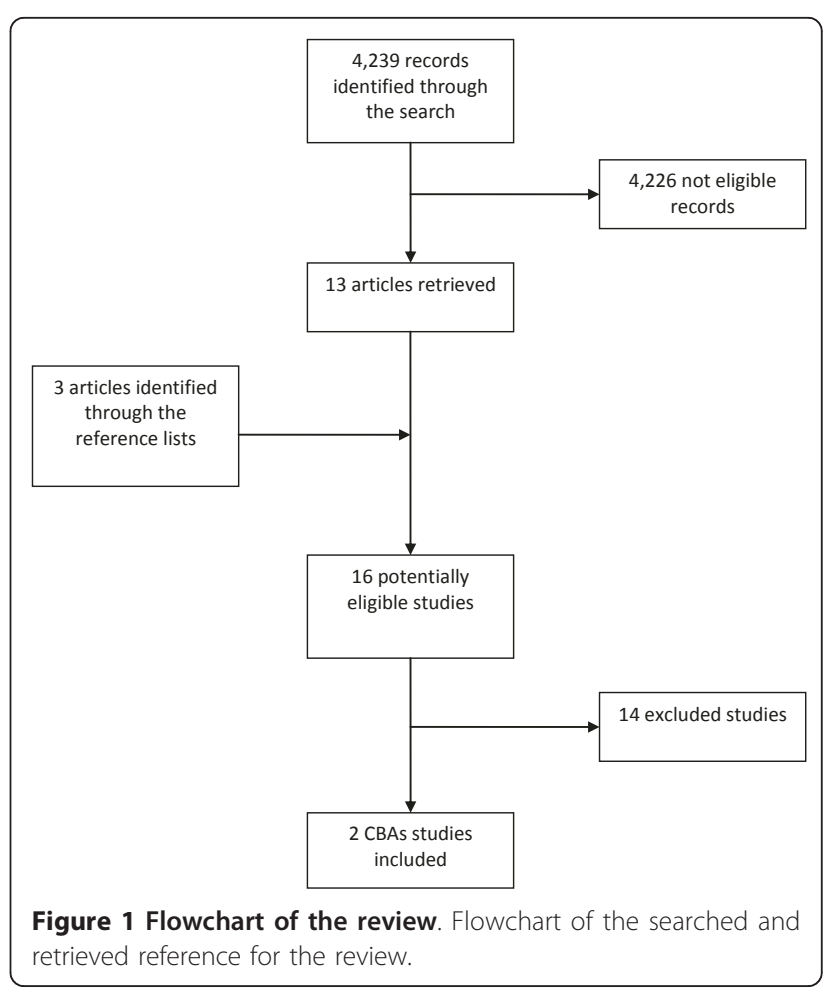


reported self-report outcome measures only (and were not measuring organisational culture), and six used designs that were excluded by the review criteria. The characteristic of the two included studies are reported in Table 1. Both of them used a CBA design to assess the impact of interventions aimed at changing organisational culture; Kinjerski [20] evaluated the impact on workrelated and personal outcomes while Larson [21] measured clinical outcomes; both were at high risk of bias (see Table 1). They both report positive results (see Tables 2 and 3).

Larson et al. [21] introduced a top-level administrative intervention using a framework for changing organisational culture on staff handwashing frequency; the purpose of the study was to measure the impact of the intervention on handwashing frequency and rates of selected nosocomial infections. The study took place in two hospitals (one serving as an intervention site and

Table 1 Characteristics of included studies

\begin{tabular}{|c|c|c|}
\hline & Larson & Kinjerski \\
\hline Study design & CBA & CBA \\
\hline Providers & Manager, medical and nurse leaders & $\begin{array}{l}\text { RNs; LPNs; RNAs; other (admin, housekeeping, food service, } \\
\text { physio) }\end{array}$ \\
\hline Patients & Adult and neonatal & Elderly long-term care residents \\
\hline Setting & Two hospitals in mid-Atlantic region & Two long-term care units, Canada \\
\hline Unit of allocation & Adult intensive care unit (ICU) and neonatal ICU & Long-term care unit \\
\hline Unit of analysis & Hospital & Long-term care unit \\
\hline Intervention & $\begin{array}{l}\text { Top-level administrative intervention using a framework for } \\
\text { changing organisational culture. Interventions included } \\
\text { dissemination of key messages, marketing approaches } \\
\text { (distribution of samples), education interventions, audit and } \\
\text { feedback, opinion leaders (supervisors). }\end{array}$ & $\begin{array}{l}\text { Organizational intervention through education sessions to } \\
\text { 'boost morale' and improve provider satisfaction with their } \\
\text { work, offering psychic rewards. } \\
\text { - 1-day workshop on 'cultivating spirit at work in long-term } \\
\text { care' } \\
\text { - 1-hour booster sessions each week at shift changes }\end{array}$ \\
\hline Control & Standard care & Standard care \\
\hline Target behaviour & Handwashing practice & $\begin{array}{l}\text { Employee spirit at work, employee wellness, job satisfaction, } \\
\text { organizational commitment, turnover, absenteeism. }\end{array}$ \\
\hline Outcomes & $\begin{array}{l}\text { a) Handwashing frequency } \\
\text { b) Nosocomial infection associated with methicillin- } \\
\text { resistant Staphylococcus aureus (MRSA) and vancomycin- } \\
\text { resistant enterococci (VRE). }\end{array}$ & $\begin{array}{l}\text { a) Health professional outcomes/process measures: decrease } \\
\text { in turnover and absenteeism; improved employee spirit at } \\
\text { work, employee wellness, job satisfaction and organizational } \\
\text { commitment. } \\
\text { b) Patient outcomes: increased focus on residents with } \\
\text { implications for Quality of Care (not stated as an outcome } \\
\text { to be measured, but reported on as a result of the } \\
\text { program). }\end{array}$ \\
\hline \multicolumn{3}{|l|}{ Risk of Bias assessment } \\
\hline $\begin{array}{l}\text { Allocation sequence } \\
\text { adequately generated }\end{array}$ & $\mathrm{NO}$ & $\mathrm{NO}$ \\
\hline $\begin{array}{l}\text { Allocation adequately } \\
\text { concealed }\end{array}$ & $\mathrm{NO}$ & NO \\
\hline $\begin{array}{l}\text { Baseline outcome } \\
\text { measurements similar }\end{array}$ & $\mathrm{NO}$ & YES \\
\hline $\begin{array}{l}\text { Baseline characteristics } \\
\text { similar }\end{array}$ & UNCLEAR & UNCLEAR \\
\hline $\begin{array}{l}\text { Incomplete outcome } \\
\text { data adequately } \\
\text { addressed }\end{array}$ & YES & YES \\
\hline $\begin{array}{l}\text { Knowledge of the } \\
\text { allocated interventions } \\
\text { adequately prevented }\end{array}$ & $\mathrm{NO}$ & $\mathrm{NO}$ \\
\hline $\begin{array}{l}\text { Protection against } \\
\text { contamination }\end{array}$ & UNCLEAR & UNCLEAR \\
\hline $\begin{array}{l}\text { Free from selective } \\
\text { outcome reporting }\end{array}$ & YES & UNCLEAR \\
\hline $\begin{array}{l}\text { Free from other risks of } \\
\text { bias }\end{array}$ & NO (one site CBA) & NO (one site CBA) \\
\hline
\end{tabular}


Table 2 Results for Larson 2000

\begin{tabular}{|c|c|c|c|c|c|c|c|c|c|c|}
\hline \multicolumn{2}{|c|}{ Outcomes } & \multicolumn{2}{|c|}{ Comparison } & \multicolumn{2}{|c|}{ Intervention } & \multirow[t]{2}{*}{ ARD } & \multicolumn{2}{|c|}{ RR $(95 \%$ Cl) } & \multicolumn{2}{|c|}{$\begin{array}{c}\text { Ratio of change } \\
\text { (baseline - follow-up) }\end{array}$} \\
\hline & & Baseline & Follow-up & Baseline & Follow-up & & Baseline & Follow-up & Comparison & Intervention \\
\hline $\begin{array}{l}\text { Frequency of } \\
\text { handwashing }\end{array}$ & $\begin{array}{c}\mathrm{N}^{\circ} \text { soap-dispensing } \\
\text { episodes/patient-care } \\
\text { days }\end{array}$ & 30.3 & 55.5 & 42.6 & 116.6 & 48.8 & $\begin{array}{l}1.4(1.3 \\
\text { to } 1.52)\end{array}$ & $\begin{array}{l}2.1(1.99 \\
\text { to } 2.21)\end{array}$ & - & - \\
\hline MRSA* & $\begin{array}{l}\text { Incident density/1,000 } \\
\text { patient-care days }\end{array}$ & 0.385 & 0.503 & 0.464 & 0.309 & 0.273 & $\begin{array}{l}1.21(0.63 \\
\text { to } 2.32)\end{array}$ & $\begin{array}{l}0.61(0.31 \\
\text { to } 1.21)\end{array}$ & $\begin{array}{l}0.181(31 \% \\
\text { increase) }\end{array}$ & $\begin{array}{l}0.07(33 \% \\
\text { decrease) }\end{array}$ \\
\hline VRE $^{* *}$ & $\begin{array}{l}\text { Incident density/1,000 } \\
\text { patient-care days }\end{array}$ & 0.700 & 0.394 & 0.464 & 0.070 & 0.088 & $\begin{array}{l}0.66(0.38 \\
\text { to } 1.14)\end{array}$ & $\begin{array}{l}0.19(0.04 \\
\text { to } 0.65)\end{array}$ & $\begin{array}{l}0.56(44 \% \\
\text { decrease) }\end{array}$ & $\begin{array}{l}0.15(85 \% \\
\text { decrease) }\end{array}$ \\
\hline
\end{tabular}

*methicillin-resistant Staphylococcus aureus.

**vancomycin-resistant enterococci.

the other as control) in the mid-Atlantic region of the USA; they had similar infection prevention and control programmes. A two-tiered strategy for the administrative intervention was developed and implemented based on Schien's framework for changing organisational culture [4] that suggested that leaders have the greatest potential for reinforcing new aspects of culture. First, top management and medical and nursing leaders agreed to provide active support for a culture change that would highlight and enforce the expectations for handwashing compliance for all healthcare workers. Second, managers responsible for implementation were given an opportunity to develop the specific elements of the intervention. This resulted in a composite

Table 3 Results (Means and ANOVA) for Kinjerski 2008

\begin{tabular}{|c|c|c|c|c|c|c|c|c|c|}
\hline \multirow[b]{2}{*}{ Outcomes } & \multirow[b]{2}{*}{ Instruments } & \multicolumn{2}{|c|}{ Comparison $^{1}$} & \multicolumn{2}{|c|}{ Intervention $^{1}$} & \multirow[t]{2}{*}{ ARD } & \multicolumn{2}{|c|}{ Main Effect } & \multirow{2}{*}{$\begin{array}{c}\text { Interaction } \\
\text { Group by Time }\end{array}$} \\
\hline & & Pretest & Posttest & Pretest & Posttest & & Group & Time & \\
\hline \multicolumn{10}{|c|}{ Work-related outcomes } \\
\hline Spirit at work & $\begin{array}{l}\text { The Spirit at Work Scale } \\
\qquad \begin{array}{l}18 \text { items } \\
(1 \rightarrow 6)\end{array}\end{array}$ & 85.6 & 84.5 & 81.2 & 90.5 & 10.4 & $F<1$ & $F(1.49)=8.62^{* *}$ & $F(1.49)=13.88^{* * *}$ \\
\hline Job satisfaction & $\begin{array}{l}\text { The Job Satisfaction Scale } \\
\qquad \begin{array}{c}14 \text { items } \\
(1 \rightarrow 7)\end{array}\end{array}$ & 81 & 77.8 & 69.7 & 76.4 & 9.9 & $F(1.40)=4.94^{*}$ & $F<1$ & $F(1.40)=7.25^{* *}$ \\
\hline $\begin{array}{l}\text { Organisational } \\
\text { commitment }\end{array}$ & $\begin{array}{l}\text { The Organisational } \\
\text { Commitment Scale } \\
15 \text { items } \\
(1 \rightarrow 7)\end{array}$ & 49.3 & 48.3 & 45.2 & 51.1 & 6.9 & $F<1$ & $F(1.50)=4.20^{*}$ & $F(1.50)=8.27^{* *}$ \\
\hline $\begin{array}{c}\text { Organisational } \\
\text { culture }\end{array}$ & $\begin{array}{l}\text { The Organisational } \\
\text { Culture Survey } \\
31 \text { items, } 6 \text { areas } \\
(1 \rightarrow 5)\end{array}$ & 116.8 & 116.7 & 101.7 & 115.3 & 13.7 & $F(1.42)=4.24^{*}$ & $F(1.42)=7.20^{*}$ & $F(1.42)=7.56^{* *}$ \\
\hline Team work & $\begin{array}{l}\text { The Organisational } \\
\text { Culture Survey } \\
(1 \rightarrow 5)\end{array}$ & 20.8 & 20.8 & 17.5 & 21.5 & 4 & $F(1.49)=2.22$ & $F(1.49)=9.76^{* *}$ & $F(1.49)=10.49^{* *}$ \\
\hline Morale/climate & $\begin{array}{l}\text { The Organisational } \\
\text { Culture Survey } \\
(1 \rightarrow 5)\end{array}$ & 18.8 & 19.2 & 16.8 & 19.7 & 3.6 & $F<1$ & $F(1.49)=10.52^{* *}$ & $F(1.49)=5.88^{*}$ \\
\hline \multicolumn{10}{|l|}{ Personal outcomes } \\
\hline Vitality & $\begin{array}{c}\text { The Vitality Scale } \\
7 \text { items } \\
(1 \rightarrow 7)\end{array}$ & 37 & 37 & 35.8 & 37.3 & 1.5 & $F<1$ & $F(1.50)=1.06$ & $F<1$ \\
\hline Life satisfaction & $\begin{array}{l}\text { Satisfaction with Life } \\
\text { Scale } \\
5 \text { items } \\
(1 \rightarrow 7)\end{array}$ & 26.5 & 28.1 & 27 & 29.8 & 1.2 & $F<1$ & $F(1.49)=10.25^{* *}$ & $F<1$ \\
\hline Orientation to life & $\begin{array}{c}\text { Sense of Coherence Scale } \\
13 \text { items } \\
(1 \rightarrow 7)\end{array}$ & 67.3 & 68.8 & 62.8 & 66.8 & 2.5 & $F(1.48)=1.56$ & $F(1.48)=4.28^{*}$ & $F<1$ \\
\hline
\end{tabular}

${ }^{1}$ Mean scores: higher score $=$ better outcomes.

${ }^{*} \mathrm{p}<0.05$; $\mathrm{p}<0.01$; *** $\mathrm{p}<0.001$. 
intervention consisting of educational programs, information materials, distribution of handwashing fact sheets and hand-hygiene products samples, and supervisory/supporting activities. Rates of nosocomial infection were calculated for both of the study hospitals as the number of cases per 1,000 patient-care days. Surveillance methods were the same in both hospitals. A surrogate for handwashing frequency was measured using counting devices placed inside every soap dispenser of four selected units (two in each hospital). In the intervention hospital, the mean handwashing frequency per patient-care day measured after six months of follow-up was higher than in the control hospital (see Table 2), but it is unclear if the analysis has taken account of the baseline imbalance. No statistically significant difference was found in methicillin-resistant Staph. aureus (MRSA) rates between the two hospitals during the follow-up phase, but the intervention hospital showed significantly lower rates of vancomycin-resistant enterococci (VRE) $(\mathrm{RR}=0.19, \mathrm{p}=0.002)$.

Kinjerski and Skrypnek [20] explored whether a 'spirit at work' intervention program could increase employee spirit at work, employee wellness, job satisfaction, and organizational commitment, and decrease absenteeism and turnover. The intervention consisted of a one day workshop, 'Cultivating Spirit at Work in Long-Term Care,' supplemented by eight weekly one hour booster sessions. The workshop focused on spirit at work what it is, personal strategies to foster it (i.e., living purposely, living spiritually, appreciating self and others, and refilling the cup), and organizational conditions to cultivate it (e.g., inspired leadership, sense of community, personal fulfilment, positive workplace culture). Participants were led through a variety of exercises that culminated in the creation of personal action plans to enhance spirit at work. Booster sessions were offered each week before and after shift change. The results show significant changes in six of the nine worker completed measures, including a measure of organisational culture (Table 3). Absenteeism rates (the per cent sick/ paid hours in five months after the workshop compared with the same five months in the previous year) were no different pre-intervention (4.2\% intervention group, $4.1 \%$ control group, $\mathrm{Chi}^{2}<1$, ns). The post-intervention difference was significant (1.7\% intervention group, $3.5 \%$ control group, $\mathrm{Chi}^{2}=127.82, d f=1, \mathrm{p}<0.001$ ). Turnover rates (per cent unit staff leaving/total staff on the unit over eight months pre- and five months post-introduction of the program) were no different pre-intervention (10.5\% intervention group, 9.8\% control group, $\mathrm{Chi}^{2}<1$, $\mathrm{ns})$. The post-intervention difference was significant (2.6\% intervention group, $16.4 \%$ control group, $\mathrm{Chi}^{2}=$ $4.49, d f=1, \mathrm{p}<0.05)$. None of the analyses were reported as adjusting for baseline imbalance.

\section{Discussion}

We identified two studies that evaluated the effects of interventions aimed at changing organisational culture. Both studies reported positive effects - one on behavioural and clinical measures, and the other on study subject reported outcome measures and two indicators of organisational performance. Whilst this may seem encouraging, there are a number of methodological issues suggesting that these results should be treated with caution.

Both studies used a controlled before-after design, with one site experiencing the intervention and one site acting as control. Therefore any intervention effect is confounded by a possible (unknown) site effect. If researchers are evaluating interventions to change organisational culture and wish to produce generalisable findings, there is no reason why they should not use designs that would allow general inferences to be made with more confidence than is possible with the currently reported studies. In addition, neither study seemed to have allowed for the apparent baseline imbalance between their groups when calculating their effect sizes.

Both studies delivered complex interventions. One study [21] set out to change organisational culture and used an appropriate framework to do so but did not report any measure of organisational culture within the study. This means that it is not possible to understand if the intervention managed to change the organisational culture. In addition, this study delivered their 'culture changing' intervention to senior and middle managers, the latter of whom then developed and delivered a series of different interventions (many of which have evidence of their ability to change behaviour in their own right), and so it is not possible to disentangle the active ingredients within what was delivered. The second study [20] set out to change spirit at work but did measure, and reported a change in, organisational culture within this context. It is not clear how much of the intervention was specifically aimed at changing organisational culture (and so could be considered for examination in other studies) and how much of the effect was just a by-product of an intervention aimed primarily at a different concept. Finally, neither study provided a comprehensive description of activities in the control group as is recommended [22] in order to facilitate interpretation of intervention effects.

It is important to consider possible reasons for why this review included only two controlled studies of culture change interventions. Whilst using well-recognised systematic review methods, the construction of the search strategy was difficult; we included terms related to culture (and also allowed the term 'climate' though we excluded the term 'safety') resulting in a broad search that had to be manually sifted by two of authors. It is possible that we missed studies within this process. 
The review would also miss unpublished studies and so publication bias remains a threat to the findings of the review.

Studies of organisational culture are most commonly found in the organisational and management research literature rather than the biomedical literature. Organisational research has context and methodological norms that differ from those of biomedicine and so trials are rare and the epistemological and methodological assumptions are different from the norms of science - as exemplified in a review by Jung et al. of organisational culture measurement instruments [12]. So, whilst there are those who seek to diagnose and subsequently change organisational culture to align it with that of highly performing organisations, they are unlikely to conduct such work within the designs included within this review. We have conducted this review using our criteria of methodological validity and are aware that these may be contested by some readers of this review. Although our perspective will have driven our sifting of the literature search, we still only identified 16 studies and only excluded six of these on our design criteria. Even had we considered these and they had all been positive, eight studies would still reflect a small and uncertain body of evidence. Given the limitations in the available evidence, and in the light of the considerable health service interest in the use of measures for organisational culture, research efforts should focus on generating evidence about the effectiveness of methods to change organisational culture to improve healthcare performance. However, given the multiplicity of measures [1,12], it may be the case that researchers need to continue to work to establish a clear definition of organisational culture and agree on reliable methods of measuring it.

At the moment the available evidence does not identify any effective, generalisable strategies to change organisational culture, and healthcare organisations considering implementing interventions aimed at changing culture should seriously consider conducting an evaluation (using a robust design, e.g., ITS) to strengthen the evidence about this topic.

\section{Conclusions}

No conclusions can be made about the effectiveness of strategies to change organisational culture to improve healthcare performance as high quality evidence on the effectiveness of strategies to change organisational culture is lacking. Researchers wishing to evaluate the effectiveness of strategies to change organisational culture should conduct evaluations using appropriately robust designs if the intent is to offer generalisable findings.

\section{Additional material}

Additional File 1: Search Strategies. Full search strategies

Additional File 2: Excluded studies. Excluded studies with reasons for exclusion

\section{Conflict of interests}

MPE is Co-Editor in Chief of Implementation Science. All decisions on this manuscript were made by another editor.

\section{Acknowledgements}

Elena Parmelli was supported by the University of Modena and Reggio Emilia, Researchers Mobility Grant 2008.

\section{Author details}

${ }^{1}$ Institute of Health and Society, Newcastle University, Baddiley-Clark Building, Richardson Road, Newcastle upon Tyne, NE2 4AX, UK. ²Department of Oncology, Hematology and Respiratory Diseases, University of Modena and Reggio Emilia, Via del Pozzo 71, 41100 Modena, Italy. ${ }^{3}$ National Institute for Health and Clinical Excellence, Level 1A, City Tower, Piccadilly Plaza, Manchester, M1 4BD, UK. ${ }^{4}$ Canadian Cochrane Centre, 1 Stewart Street, Rm 227, Ottawa, ON K1N 6N5, Canada.

\section{Authors' contributions}

MPE conceived of the idea for the review. EP wrote the protocol and led the writing of the manuscript. All authors contributed to the literature sifting, data extraction, and writing. All authors approved the final submitted version of the manuscript.

Received: 2 December 2010 Accepted: 3 April 2011

Published: 3 April 2011

\section{References}

1. Mannion R, Konteh FH, Davies HT: Assessing organisational culture for quality and safety improvement: a national survey of tools and tool use. Qual Saf Health Care 2009, 18(2):153-156.

2. Alvesson M: Cultural perspectives on organisations. Cambridge University Press; 1995.

3. Balogun J, Hailey V: Exploring strategic change. London: Prentice Hall; 2004

4. Schien E: Organisational Culture and Leadership. San Francisco: JosseyBass; 1995.

5. Konteh FH, Mannion R, Davies H: Clinical governance views on culture and quality improvement. Clinical Governance: An International Journal 2008, 13(3):200-207.

6. Scott T, Mannion R, Marshall M, Davies H: Does organisational culture influence health care performance? A review of the evidence. $J$ Health Serv Res Policy 2003, 8(2):105-117.

7. Davies HT, Nutley SM, Mannion R: Organisational culture and quality of health care. Qual Health Care 2000, 9(2):111-119.

8. Kennedy I: Learning from Bristol: public inquiry into children's heart surgery at the Bristol Royal Infirmary 1984-1995. London: Stationery Office; 2001.

9. Scott JT, Mannion R, Davies H: Health Care Performance and Organisational Culture. Oxford: Radcliff Medical; 2003.

10. Ormrod S: Organisational culture in health service policy and research third way: political fad or policy development? Policy Polit 2003, 31:227-237.

11. Ashcroft DM, Morecroft C, Parker D, Noyce PR: Safety culture assessment in community pharmacy: development, face validity, and feasibility of the Manchester Patient Safety Assessment Framework. Qual Saf Health Care 2005, 14(6):417-421.

12. Jung $T$, Scott $T$, Davies $H$, Bower $P$, Whalley $D$, McNally R, Mannion R: Instrumentsfor Exploring Organizational Culture: A Review of the Literature. Public Administration Review 2009, 69(6):1087-1096.

13. Scott JT, Mannion R, Davies HT, Marshall MN: Implementing culture change in health care: theory and practice. Int J Qual Health Care 2003, 15(2):111-118. 
14. Mannion R, Davies HT, Marshall MN: Cultural characteristics of "high" and "low" performing hospitals. J Health Organ Manag 2005, 19(6):431-439.

15. Shifting the balance of power within the NHS: securing delivery. London: Department of Health; 2000.

16. Institute of Medicine: To Err is Human: Building a Safer Health System. Washington DC: National Academy Press; 1999.

17. Smith P: Measuring Up: Improving Health System Performance in OECD Countries. Paris: OECD; 2000.

18. Ramsay CR, Matowe L, Grilli R, Grimshaw JM, Thomas RE: Interrupted time series designs in health technology assessment: lessons from two systematic reviews of behavior change strategies. Int I Technol Assess Health Care 2003, 19(4):613-623.

19. Higgins JP, Green S: Cochrane Handbook for Systemativ Reviews of Interventions. John Wiley \& Sons; 2008.

20. Kinjerski V, Skrypnek BJ: The promise of spirit at work: increasing job satisfaction and organizational commitment and reducing turnover and absenteeism in long-term care. J Gerontol Nurs 2008, 34(10):17-25, quiz 26-17.

21. Larson EL, Early E, Cloonan P, Sugrue S, Parides M: An organizational climate intervention associated with increased handwashing and decreased nosocomial infections. Behav Med 2000, 26(1):14-22.

22. Michie S, Fixsen D, Grimshaw JM, Eccles MP: Specifying and reporting complex behaviour change interventions: the need for a scientific method. Implement Sci 2009, 4:40.

doi:10.1186/1748-5908-6-33

Cite this article as: Parmelli et al:: The effectiveness of strategies to change organisational culture to improve healthcare performance: a systematic review. Implementation Science 2011 6:33.

\section{Submit your next manuscript to BioMed Central and take full advantage of:}

- Convenient online submission

- Thorough peer review

- No space constraints or color figure charges

- Immediate publication on acceptance

- Inclusion in PubMed, CAS, Scopus and Google Scholar

- Research which is freely available for redistribution

Submit your manuscript at www.biomedcentral.com/submit 